\title{
Rectangular Strain-Rosette Method for Measuring the Mode I Stress-Intensity Factor $\mathrm{K}_{\mathrm{I}}$ and T-stress
}

\author{
Adel Hamdi \\ El Manar Preparatory Institute for \\ Engineering Studies, \\ Tunis, Tunisia \\ ahamdi.tu@gmail.com
}

\author{
Noureddine Benseddiq \\ Lille Laboratory of Mechanics \\ University of Lille \\ Villeneuve d'Ascq, France \\ noureddine.benseddiq@univ-lille1.fr
}

\author{
Fatah Mejni \\ Lille Laboratory of Mechanics \\ University of Lille \\ Villeneuve d'Ascq, France \\ fatah.mejni@gmail.com
}

\begin{abstract}
In this paper, a new experimental technique for measuring Stress Intensity Factor (SIF) and T-stress under mode I loading is developed. The expressions of the normal and tangential strains close to the crack tip are given using the first five terms of the generalized Westergaard formulation. In order to accurately determine the SIF and T-stress, the method exploits the optimal positioning of a rectangular strain gage rosette near a crack tip in mode I. Thus, errors due to the higher order terms of the asymptotic expansion are eliminated. Finally, a comparison of the analytical results with finite element calculations, for different specimen dimensions, is carried out.
\end{abstract}

Keywords-fracture toughness; stress intensity factor; t-stress; strain gage; finite element method

\section{INTRODUCTION}

In Linear Elastic Fracture Mechanics (LEFM), the primary focus is generally based upon the Stress Intensity Factor (SIF), as a critical parameter, that defines whether an existing crack in a specimen grows or not. It is proportional to the first singular term of the Williams [1] series expansion. Accurate values of SIF are necessary to predict and prevent fracture in components. The approach, based on a single parameter, is not able to fully interpreting some circumstances that occur. Nevertheless, there is experimental evidence [2, 3] showing that the constant stress may affect fracture mechanics properties. A second parameter, introduced in [4], also plays an important role in fracture processes and commonly referred to as the $T$-stress, which is the second non-singular term in the Williams [1] series expansion. It represents the stress acting parallel to the crack plane and it is independent of the distance from the crack tip and proportional to the applied stresses. $T$ stress plays a key role in stability of the crack paths and it has a significant influence on the shape and the size of the plastic zone around the crack tip in ductile materials [5-8]. To determine the SIF in cracked specimens, three methods have been developed over the last years [9], analytical, numerical and experimental. Due to the complexity of the mathematical developments, analytical methods are limited to simple configurations and therefore one must resort to numerical or experimental methods [9]. Experimental techniques, such as the compliance $[10,11]$, photo-elasticity [12-14], caustics [15, $16]$ and strain gage $[17,18]$ methods were developed. Strain gage technique is the most common method used to analyse stress field. It is relatively simple because it can measure surface strains accurately directly within strain gradient zones. The use of strain gages to determine the SIF near the crack tip has been suggested [19]. Other experimental methods like compliance measurements and photo-elasticity were developed $[20,21]$, however, they have some limitations in the case of opaque materials. Authors in [17] were the first to develop a simple strain gage technique allowing to measure the static mode I SIF of isotropic bodies. They identified the region, around the crack tip, for accurate measurement of the strains. To describe the strain field, the authors used a truncated strain series, based upon the generalized Westergaard approach [22]. The main advantage of the Dally and Sanford method is that only one strain gage is sufficient to determine the mode I SIF, which can be placed far away from the crack tip. However, this technique requires prior knowledge of the strain representation which is a function of the specimen's geometry and the applied loading. On one hand, authors in [23] and [24] extended the technique described in [17] to mixed mode SIF and dynamic SIF, respectively. On the other hand, authors in [25] and [26] used the technique from [17] with static and dynamic cracks, respectively. Note that no procedure for selection of radial location of strain gage was reported in their works. Authors in [27] determined, for some cracked samples, the dynamic SIF in isotropic materials by placing strain gages within the singularity dominated zone. In [31], authors determined, using strain gage technique, mode I SIF by solving large number of deterministic equations. Other strain gage methods specifically designed for measuring static mode I SIF have been proposed in [28] and [29].

Authors in [28] used two strain gages for measuring the mode I SIF. However, the locations (radial distances) of the strain gages necessitate, beforehand, the knowledge of the plastic zone size. Authors in [29] developed a single strain gage technique based on the asymptotic strain expressions. They suggested that strain gages could be placed at distances, from the crack tip, greater than half the specimen thickness measured. Their results showed that the measured normalized SIF is a function of the applied loads, the thickness of the specimen and the angular position from the crack. Recently, another technique was proposed [30], using a three strain gage rosette to determine the mixed mode SIF. Placing the rosette 
near the crack tip but outside the plastic zone was suggested. One can conclude from the literature investigation that the single strain gage method [17] is widely used compared to other strain gage techniques. While some recommendations available for radial locations of strain gage were developed in $[26,28,30]$. Note that, in their works, also, no procedures were mentioned for determination of valid radial locations. The only attempts have been made by authors in [32-34] to determine the optimal radial locations using single and double strain gage cracked configurations. In fact, in their works, they $[32,33]$ presented a new methodology based upon the Finite Element Analysis (FEA), supported by theoretical foundations. Experimental validation of the methodology for determination of maximum permissible strain gage radial location is presented in [34]. To numerically and analytically determine the $T$-stress, different methods have been proposed in the literature for different types of specimens. Authors in [35, 36] showed that the sign and the magnitude of the $T$-stress substantially change the size and shape of the crack tip plastic zone. In $[37,38]$ authors showed that $T$-stress can be evaluated using a modified $J$-integral based on FEA. In [39] authors have studied the stress field around the crack front for a single edge specimen subjected to bending and tension to determine the $T$ stress in a three-dimensional model. Similar investigation was conducted in [40] for center cracked plates. In [41] authors have evaluated elasto-dynamic $T$-stress by using the interaction integral from the boundary element solution. In [42] authors have developed a stress difference method to evaluate the $T$ stress with a crack problem. Authors in [43] determined, using FEA, the $T$-stress and obtained stabilised $T$-stress distribution along ligament. Despite the importance of the $T$-stress, the experimental techniques, dealing with accurate measurement of $T$-stress are very limited in the literature. Inspired by the fact that Thermoelastic Stress Analysis (TSA) is an ideal technique for the determination of mode I, II and mixed SIF [44, 45], authors in [46] have developed a technique to determine the $T$ stress and mixed-mode SIF from TSA images. Also, the same authors [47] developed a technique to determine the $T$-stress and mode I SIF from Digital Image Correlation (DIC). FE simulation was undertaken and good agreement between experimental and numerical results was found. They concluded that the technique is applicable for fatigue crack studies and $T$ stress determinations. An extension was made [48] to the method described in [17] to calculate the mode I SIF and $T$ stress. They used rectangular rosettes to evaluate the $T$-stress.

This work deals with the development of a new method for SIF and $T$-stress determination by using one or two rectangular rosettes. As a first step, the formulation of the normal strains, close to the crack tip, are given using the first five terms of the generalized Westergaard formulation [22]. Then, in a second step, these formulations are applied to analytically determine the optimum locations for the rectangular rosette to eliminate the errors due to higher order terms of the asymptotic expansion.

\section{PROBLEM FORMULATION}

In [17] was showed that the region around a crack tip (traction free crack faces) can be divided into three zones: very near field (zone I), near field (zone II) and far field (zone III) as shown in Figure 1. Zone I is closed to the crack tip and the first singular term of the strain series is sufficient to represent the strain field. However, it is not a valid zone for accurate measurement of strains because the stress state is threedimensional [49] and the strain field is severely affected by the plasticity. Also, errors in measuring the position of the strain gage are excessive if they are located very close to the crack tip. Zone III is not either suitable for strain calculation because a large number of terms in the strain series is required to obtain accurate results. Therefore, it was identified [17] that the intermediate region (zone II) is favourable and optimum for accurate measurement of the strains. In this zone, a singular term and a small number of higher order terms correctly describe the strain field.

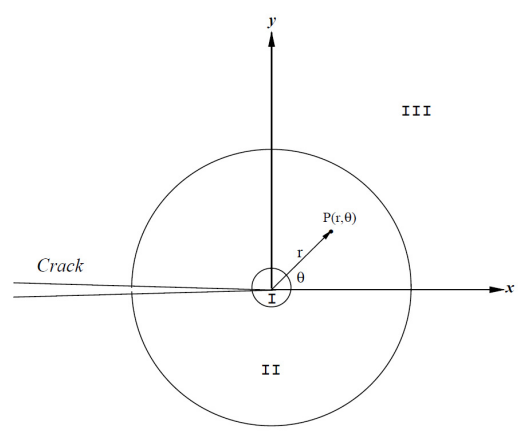

Fig. 1. Different regions around the crack tip.

\section{A. Multi-term Representation of the Strain Field}

The equations of the near strain field are calculated using the generalized Westergaard approach [22]. Thus, the modified Airy stress function is given by:

$$
\varphi=\mathfrak{R}(\overline{\bar{Z}}(z))+y \mathfrak{I}(\bar{Z}(z))+y \mathfrak{I}(\bar{Y}(z))
$$

Where

$$
\frac{d \overline{\bar{Z}}}{d z}=\bar{Z}, \frac{d \bar{Z}}{d z}=Z, \frac{d \bar{Y}}{d z}=Y
$$

and the complex analytic functions $\mathrm{Z}(\mathrm{z})$ and $\mathrm{Y}(\mathrm{z})$ are defined as:

$$
\begin{aligned}
& Z(z)=\sum_{n=0}^{N} A_{n} z^{n-\frac{1}{2}}=\frac{K_{I}}{\sqrt{2 \pi z}}+\sum_{n=1}^{N} A_{n} z^{n-\frac{1}{2}} \\
& Y(z)=\sum_{m=0}^{M} B_{m} z^{m}=\frac{\sigma_{0 x}}{2}+\sum_{m=1}^{M} B_{m} z^{m}
\end{aligned}
$$

For a given problem, these series, in terms of the complex variable $z=x+i y$, contain an infinite number of coefficients $\left(A_{0}, A_{1}, A_{2}, \ldots \ldots, A_{\infty} ; B_{0}, B_{1}, B_{2}, \ldots \ldots, B_{\infty}\right)$ that can be determined using the boundary conditions. The stress components for the entire domain are represented in [17] as:

$$
\begin{aligned}
\sigma_{x x} & =\mathfrak{R}(Z)-y\left[\mathfrak{I}\left(Z^{\prime}\right)+\mathfrak{I}\left(Y^{\prime}\right)\right]+2 \mathfrak{R}(Y) \\
\sigma_{y y} & =\mathfrak{R}(Z)+y\left[\mathfrak{I}\left(Z^{\prime}\right)+\mathfrak{I}\left(Y^{\prime}\right)\right] \\
\tau_{x y} & =-y\left[\mathfrak{R}\left(Z^{\prime}\right)+\mathfrak{R}\left(Y^{\prime}\right)\right]-\mathfrak{I}(Y)
\end{aligned}
$$


By substituting (5) into the plane stress-strain relations:

$$
\begin{aligned}
& \varepsilon_{x x}=\frac{1}{E}\left(\sigma_{x x}-v \sigma_{y y}\right) \\
& \varepsilon_{y y}=\frac{1}{E}\left(\sigma_{y y}-v \sigma_{x x}\right) \\
& \gamma_{x y}=\frac{1}{\mu} \tau_{x y}
\end{aligned}
$$

one can obtain the following generalized equations of the strain field:

$$
\begin{aligned}
& E \varepsilon_{x x}=f_{1} \mathfrak{R}(Z)-f_{2} y\left[\mathfrak{I}\left(Z^{\prime}\right)+\mathfrak{I}\left(Y^{\prime}\right)\right]+2 \mathfrak{R}(Y) \\
& E \varepsilon_{y y}=f_{1} \mathfrak{R}(Z)+f_{2} y\left[\mathfrak{I}\left(Z^{\prime}\right)+\mathfrak{I}\left(Y^{\prime}\right)\right]-2 v \mathfrak{R}(Y) \\
& \mu \gamma_{x y}=-y\left[\mathfrak{R}\left(Z^{\prime}\right)+\mathfrak{R}\left(Y^{\prime}\right)\right]-\mathfrak{I}(Y)
\end{aligned}
$$$$
\text { where } f_{1}=1-v, f_{2}=1+v \text {. }
$$

The substitution of the complex functions $Z(z)$ and $Y(z)$, from (3) and (4), gives an exact representation of the strain field, in the domain, with an infinite number of coefficients $A_{n}$ and $\mathrm{B}_{\mathrm{m}}$. It is assumed that the strain field in the zone II is sufficiently represented, by the five terms series, $\mathrm{n}=0,1,2$ and $\mathrm{m}=0,1$, with the unknown coefficients $\mathrm{A}_{0}, \mathrm{~A}_{1}, \mathrm{~A}_{2}, \mathrm{~B}_{0}$ and $\mathrm{B}_{1}$. In this zone, the five terms representation of the strain field is expressed as:

$$
\begin{aligned}
E \varepsilon_{x x} & =\cos (\theta / 2)\left[f_{1}-f_{2} \sin (\theta / 2) \sin (3 \theta / 2)\right] A_{0} r^{-\frac{1}{2}} \\
+ & 2 B_{0} r^{0}+\cos (\theta / 2)\left[f_{1}+f_{2} \sin ^{2}(\theta / 2)\right] A_{1} r^{\frac{1}{2}}+2 \cos (\theta) B_{1} \\
+ & {\left[f_{1} \cos (3 \theta / 2)-\frac{3}{2} f_{2} \sin (\theta) \sin (\theta / 2)\right] A_{2} r^{\frac{3}{2}}+O\left(r^{2}\right) } \\
E \varepsilon_{y y}= & \cos (\theta / 2)\left[f_{1}+f_{2} \sin (\theta / 2) \sin (3 \theta / 2)\right] A_{0} r^{-\frac{1}{2}}-2 v B_{0} r^{0} \\
+ & \cos (\theta / 2)\left[f_{1}-f_{2} \sin ^{2}(\theta / 2)\right] A_{1} r^{\frac{1}{2}}-2 v \cos (\theta) B_{1} r \\
+ & {\left[f_{1} \cos (3 \theta / 2)+\frac{3}{2} f_{2} \sin (\theta) \sin (\theta / 2)\right] A_{2} r^{\frac{3}{2}}+O\left(r^{2}\right) } \\
E \gamma_{x y} & =f_{2} \sin (\theta)\left[\cos (3 \theta / 2) A_{0} r^{-\frac{1}{2}}-\cos (\theta / 2) A_{1} r^{\frac{1}{2}}\right.
\end{aligned}
$$

In these equations, $A_{0}, A_{1}, A_{2}, B_{0}$ and $B_{1}$ are determined using the specimen geometry and the boundary conditions. The coefficients $A_{0}$ and $B_{0}$ are proportional, under a mode I loading, to the SIF $K_{I}$ and the $T$-stress, respectively:

$$
\begin{aligned}
& K_{I}=\sqrt{2 \pi} A_{0} \\
& T=2 B_{0}
\end{aligned}
$$

B. Five-Term Strain Field Relative to a Rotated Coordinate System

The strains relative to a rotated coordinate system $(\alpha, \beta)$, with its origin at an arbitrary point $P(r, \theta)$ as defined in Figure 2 , are determined from the first strain invariant as:

$$
\varepsilon_{\alpha \alpha}+\varepsilon_{\beta \beta}=\varepsilon_{x x}+\varepsilon_{y y}
$$

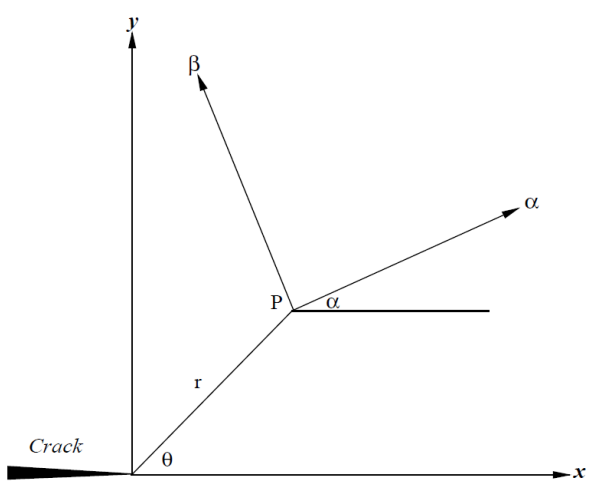

Fig. 2. Strain gage location and orientation [17].

The complex form of the strain transformation equations is expressed as the following form:

$$
\varepsilon_{\beta \beta}-\varepsilon_{\alpha \alpha}+i \gamma_{\alpha \beta}=\left(\varepsilon_{y y}-\varepsilon_{x x}+i \gamma_{x y}\right) e^{2 i \alpha}
$$

For an angle $\alpha$ that coincides with $\theta$, substituting (7) into (14) leads to:

$$
\begin{aligned}
E \varepsilon_{r r} & =f_{1}[\mathfrak{R}(Z)+\mathfrak{R}(Y)] \\
- & f_{2}\left(y\left[\mathfrak{I}\left(Z^{\prime}\right)+\mathfrak{I}\left(Y^{\prime}\right)\right]-\mathfrak{R}(Y)\right) \cos (2 \theta) \\
- & f_{2}\left(y\left[\mathfrak{R}\left(Z^{\prime}\right)+\mathfrak{R}\left(Y^{\prime}\right)\right]+\mathfrak{I}(Y)\right) \sin (2 \theta) \\
E \varepsilon_{\theta \theta} & =f_{1}[\mathfrak{R}(Z)+\mathfrak{R}(Y)] \\
& +f_{2}\left(y\left[\Im\left(Z^{\prime}\right)+\mathfrak{I}\left(Y^{\prime}\right)\right]-\mathfrak{R}(Y)\right) \cos (2 \theta) \\
& +f_{2}\left(y\left[\mathfrak{R}\left(Z^{\prime}\right)+\mathfrak{R}\left(Y^{\prime}\right)\right]+\mathfrak{I}(Y)\right) \sin (2 \theta)
\end{aligned}
$$

Replacing $n=0,1,2$ and $m=0,1$ in (3) and (4) and substituting the results for the truncated series into (15) and (16) gives:

$$
\begin{aligned}
E \varepsilon_{r r} & =\left[f_{1} \cos \left(\frac{\theta}{2}\right)+\frac{1}{4} f_{2}\left(\cos \left(\frac{\theta}{2}\right)-\cos \left(\frac{3 \theta}{2}\right)\right)\right] A_{0} r^{-\frac{1}{2}} \\
& +\left[f_{1}+f_{2} \cos (2 \theta)\right] B_{0} r^{0} \\
& +\left[f_{1} \cos \left(\frac{\theta}{2}\right)-\frac{1}{4} f_{2}\left(\cos \left(\frac{\theta}{2}\right)-\cos \left(\frac{5 \theta}{2}\right)\right)\right] A_{1} r^{\frac{1}{2}} \\
& +\left[f_{1} \cos (\theta)-\frac{1}{2} f_{2}(\cos (\theta)-3 \cos (3 \theta))\right] B_{1} r \\
& +\left[f_{1} \cos \left(\frac{3 \theta}{2}\right)-\frac{3}{4} f_{2}\left(\cos \left(\frac{3 \theta}{2}\right)-\cos \left(\frac{7 \theta}{2}\right)\right)\right] A_{2} r^{\frac{3}{2}} \\
& +O\left(r^{2}\right)
\end{aligned}
$$




$$
\begin{aligned}
E \varepsilon_{\theta \theta} & =\left[f_{1} \cos \left(\frac{\theta}{2}\right)-\frac{1}{4} f_{2}\left(\cos \left(\frac{\theta}{2}\right)-\cos \left(\frac{3 \theta}{2}\right)\right)\right] A_{0} r^{-\frac{1}{2}} \\
& +\left[f_{1}-f_{2} \cos (2 \theta)\right] B_{0} r^{0} \\
& +\left[f_{1} \cos \left(\frac{\theta}{2}\right)+\frac{1}{4} f_{2}\left(\cos \left(\frac{\theta}{2}\right)-\cos \left(\frac{5 \theta}{2}\right)\right)\right] A_{1} r^{\frac{1}{2}} \\
& +\left[f_{1} \cos (\theta)+\frac{1}{2} f_{2}(\cos (\theta)-3 \cos (3 \theta))\right] B_{1} r \\
& +\left[f_{1} \cos \left(\frac{3 \theta}{2}\right)+\frac{3}{4} f_{2}\left(\cos \left(\frac{3 \theta}{2}\right)-\cos \left(\frac{7 \theta}{2}\right)\right)\right] A_{2} r^{\frac{3}{2}} \\
& +O\left(r^{2}\right)
\end{aligned}
$$

\section{Rectangular Strain-rosette Location and Orientation}

Note that it is possible to obtain the data necessary to determine $K_{I}$ and $T$-stress by using single or two rectangular rosettes placed in zone II. Equations (17) and (18) are used to determine an optimal location of the rosette capable to eliminate some higher order terms. Indeed, two approaches will be described herein to illustrate the procedure: 1) the single rosette is used to provide the data necessary to evaluate $K_{I}$ with a three term solution and $T$-stress with a two term solution; 2) the two rosettes are used to provide the data necessary to evaluate $K_{I}$ and $T$-stress with a four term solution. Each of these two approaches will be developed below as an individual case.

\section{C.1. Case I: Single Rectangular Rosette}

- $K_{I}$ determination with three term solution

The singular term $A_{0}$ can be calculated along any direction $\theta$, where the constant term $B_{0}$ vanishes or can be set to zero by superposing $\varepsilon_{r r}$ with an appropriate fraction of $\varepsilon_{\theta \theta}$. Using (17) and (18), it is evident that the constant $B_{0}$ will vanish if:

$$
\begin{aligned}
& \frac{E}{f_{1} f_{2}}\left(\left[f_{1}-f_{2} \cos (2 \theta)\right] \varepsilon_{r r}-\left[f_{1}+f_{2} \cos (2 \theta)\right] \varepsilon_{\theta \theta}\right)= \\
& \quad-2 \cos ^{3}(\theta / 2)\left[1-8 \sin ^{2}(\theta / 2)\right] A_{0} r^{-\frac{1}{2}} \\
& \quad-2 \cos ^{3}(\theta / 2)\left[1-4 \sin ^{2}(\theta / 2)\right] A_{1} r^{\frac{1}{2}}-4 \sin (\theta) \sin (2 \theta) B_{1} r \\
& \quad-2 \cos ^{3}(\theta / 2)\left[4 \sin ^{2}(\theta)-12 \sin ^{2}(\theta / 2)+1\right] A_{2} r^{\frac{3}{2}}+O\left(r^{2}\right)
\end{aligned}
$$
if:

Considering (19), note that the term A1 can be eliminated

$$
\theta= \pm \frac{\pi}{3}
$$

When substituting (20) into (19), one can obtain the following relation:

$$
\begin{aligned}
E\left[\frac{\varepsilon_{r r}-\varepsilon_{\theta \theta}}{f_{2}}+\frac{\varepsilon_{r r}+\varepsilon_{\theta \theta}}{2 f_{1}}\right]= \\
\quad \frac{3 \sqrt{3}}{4} A_{0} r^{-\frac{1}{2}}-3 B_{1} r-\frac{3 \sqrt{3}}{4} A_{2} r^{\frac{3}{2}}+O\left(r^{2}\right)
\end{aligned}
$$

This result indicates that a single two element rectangular rosette can provide the necessary data to calculate the $K_{I}$, with a three term solution, if $\theta$ is selected as (20). Substituting (11) into (21), the expression of $K_{I}$ can be written as:

$$
\begin{aligned}
& K_{I} \approx \frac{2 \sqrt{2 \pi r} E\left[(2 \kappa+1) \varepsilon_{r r}-(2 \kappa-1) \varepsilon_{\theta \theta}\right]}{3 \sqrt{3} f_{1}} \\
& \text { where } \quad \kappa=\frac{f_{1}}{f_{2}}=\frac{1-v}{1+v}
\end{aligned}
$$

Whatever the type of used material, (22) represents the relation between $K_{I}$ and the normal strains $\varepsilon_{r r}$ and $\varepsilon_{\theta \theta}$. It can be measured using two elements of a rectangular rosette, placed in zone II, along a radial line drawn from the crack tip $\theta= \pm 60^{\circ}$. For example, when considering an aluminium specimen with $v=1 / 3$, the substitution of $f_{1}=2 / 3$ and $\kappa=1 / 2$ into (22) gives:

$$
K_{I} \approx \frac{2 \sqrt{2 \pi r} E \varepsilon_{r r}}{\sqrt{3}}
$$

One can notice from (23) that, for an aluminium material, a single strain gage is sufficient to provide the data necessary to evaluate $K_{I}$ value. Note that (23) is the first formula proposed by authors in [17].

\section{- $\quad T$-stress determination with two term solution}

Generally, the advantage to use a two strain gage rosettes is to providing the first two terms of the asymptotic expansion. Therefore, it is possible to obtain the necessary data to determine the $T$-stress, from a two-term representation, by using the same rectangular rosette placed in zone II along $\theta= \pm$ $\pi / 3$. It is clear that (17) and (18) subjected to the restriction of (20), respectively, lead to:

$$
\begin{aligned}
E \varepsilon_{r r} & =\frac{\sqrt{3}}{8}\left(4 f_{1}+f_{2}\right) A_{0} r^{-\frac{1}{2}}+\frac{1}{2}\left(2 f_{1}-f_{2}\right) B_{0} r^{0} \\
& +\frac{\sqrt{3}}{4}\left(2 f_{1}-f_{2}\right) A_{1} r^{\frac{1}{2}}+\frac{1}{4}\left(2 f_{1}-7 f_{2}\right) B_{1} r \\
& -\frac{3 \sqrt{3}}{8} A_{1} r^{\frac{3}{2}}+O\left(r^{2}\right) \\
E \varepsilon_{\theta \theta} & =\frac{\sqrt{3}}{8}\left(4 f_{1}-f_{2}\right) A_{0} r^{-\frac{1}{2}}+\frac{1}{2}\left(2 f_{1}+f_{2}\right) B_{0} r^{0} \\
& +\frac{\sqrt{3}}{4}\left(2 f_{1}+f_{2}\right) A_{1} r^{\frac{1}{2}}+\frac{1}{4}\left(2 f_{1}+7 f_{2}\right) B_{1} r \\
+ & \frac{3 \sqrt{3}}{8} A_{1} r^{\frac{3}{2}}+O\left(r^{2}\right)
\end{aligned}
$$

If (24) and (25) are truncated after the first two terms, their resolutions directly provide the expressions of $K_{I}$ and $T$-stress. In this context, it is important to mention that $K_{I}$ is determined from a three term representation because the coefficients associated to $B_{0}$ and $A_{1}$ are proportional with a same factor of proportionality. Therefore, the elimination of one of these two terms leads necessarily to the elimination of the other one. If 
we use a two term description of the strain field around the crack tip, the natural elimination of $A_{0}$ along the considered direction can be exploited to determine the $T$-stress. Now, considering (24) and (25), it is evident that the dominant term $A_{0}$ vanishes if:

$$
\begin{aligned}
\frac{E}{f_{1} f_{2}}[( & \left.\left.4 f_{1}-f_{2}\right) \varepsilon_{r r}-\left(4 f_{1}+f_{2}\right) \varepsilon_{\theta \theta}\right] \\
= & -6 B_{0} r^{0}-3 \sqrt{3} A_{1} r^{\frac{1}{2}} \\
& -15 B_{1} r-3 \sqrt{3} A_{2} r^{\frac{3}{2}}+O\left(r^{2}\right)
\end{aligned}
$$

This result indicates that the same rectangular rosette, used to calculate $K_{I}$, can be employed also to provide the data necessary to determine the $T$-stress from a two term representation. Substituting (12) into (26), the expression of the T-stress becomes:

$$
T \approx-\frac{E\left[(4 \kappa-1) \varepsilon_{r r}-(4 \kappa+1) \varepsilon_{\theta \theta}\right]}{3 f_{1}}
$$

For example, when considering again the aluminium material with $v=1 / 3$, the substitution of $f_{1}=2 / 3$ and $\kappa=1 / 2$ into (27) gives:

$$
T \approx-\frac{E\left(\varepsilon_{r r}-3 \varepsilon_{\theta \theta}\right)}{2}
$$

The expressions (22) and (27) indicate that, when a rectangular rosette is placed in zone II along $\theta= \pm 60^{\circ}$, the measured strains $\varepsilon_{r r}$ and $\varepsilon_{\theta \theta}$ allow to get the data necessary to evaluate $K_{I}$ and $T$-stress from a representation with three and two terms, respectively.

\section{C.2. Case II: Two rectangular rosettes}

- $K_{I}$ determination with four term solution

It is possible to obtain the data necessary to determine the $K_{I}$ value, from a four term representation, using two rectangular strain rosettes placed in two discrete locations in zone II with the same value of $\theta= \pm 60^{\circ}$. The four strain gage measurements, $\varepsilon_{r r A}, \varepsilon_{\theta \theta A}, \varepsilon_{r r B}, \varepsilon_{\theta \theta B}$, and their respective positions $r_{A}, r_{B}$ and $\theta_{A}=\theta_{B}$ are used to solve (21) for $A_{0}$ and $B_{1}$. Thus, when solving (21), for $A_{0}$ (or $K_{I}$ ) and $B_{1}$, using data obtained from rosettes $R_{A}$ and $R_{B}$, one can write:

$$
\begin{aligned}
& K_{I} \approx \frac{2 E \sqrt{2 \pi r_{A}}\left[(2 \kappa+1)\left(\varepsilon_{r r_{A}}-q \varepsilon_{r r_{B}}\right)-(2 \kappa-1)\left(\varepsilon_{\theta \theta_{A}}-q \varepsilon_{\theta \theta_{B}}\right)\right]}{3 \sqrt{3} f_{1}\left(1-q^{\frac{3}{2}}\right)} \\
& B_{1} \approx \frac{E\left[(2 \kappa+1)\left(q^{\frac{1}{2}} \varepsilon_{r r_{A}}-\varepsilon_{r r_{B}}\right)-(2 \kappa-1)\left(q^{\frac{1}{2}} \varepsilon_{\theta \theta_{A}}-\varepsilon_{\theta \theta_{B}}\right)\right]}{6 f_{1} r_{B}\left(1-q^{\frac{3}{2}}\right)}
\end{aligned}
$$

where $r_{A}=q r_{B}$. Equations (29) and (30) can be rewritten as the following form:

$$
\begin{aligned}
K_{I} \approx & \frac{K_{I_{A}}-q^{\frac{3}{2}} K_{I_{B}}}{1-q^{\frac{3}{2}}} \\
B_{1} \approx & \frac{\sqrt{3}\left(q^{\frac{1}{2}} K_{I_{A}}-K_{I_{B}}\right)}{4 \sqrt{2 \pi q}\left(1-q^{\frac{3}{2}}\right) r_{B}^{\frac{3}{2}}}
\end{aligned}
$$

where $K_{I A}$ and $K_{I B}$ are calculated from (22).

These are the SIF evaluated, by the data of $R_{A}$ and $R_{B}$, respectively, using a three term approach. To bring out the simplicity of our approach, consider again the aluminium specimen $\left(v=1 / 3, f_{1}=2 / 3\right.$ and $\left.\kappa=1 / 2\right)$. Equations (31) and (32) become:

$$
\begin{aligned}
K_{I} \approx \frac{2 E \sqrt{2 \pi r_{A}}\left(\varepsilon_{r r_{A}}-q \varepsilon_{r r_{B}}\right)}{\sqrt{3}\left(1-q^{\frac{3}{2}}\right)} \\
B_{1} \approx \frac{E\left(q^{\frac{1}{2}} \varepsilon_{r r_{A}}-\varepsilon_{r r_{B}}\right)}{2 r_{B}\left(1-q^{\frac{3}{2}}\right)}
\end{aligned}
$$

It is clearly shown from (33) and (34) that, in this case, two strain gages are sufficient to evaluate $K_{I}$ and $B_{1}$ values. Note that (33) is the second formula proposed in [17], the authors of which used two strain gages, to determine the $K_{I}$ value for an aluminium specimen.

- $\quad T$-stress determination with four-term solution

Using the same data obtained with the rosettes $R_{A}$ and $R_{B}$ and solving (26), for $B_{0}$ or $T$-stress, gives:

$$
\begin{aligned}
T & \approx-\frac{E\left[(4 \kappa-1)\left(\varepsilon_{r r_{A}}-q^{\frac{1}{2}} \varepsilon_{r r_{B}}\right)-(4 \kappa+1)\left(\varepsilon_{\theta \theta_{A}}-q^{\frac{1}{2}} \varepsilon_{\theta \theta_{B}}\right)\right]}{3 f_{1}\left(1-q^{\frac{1}{2}}\right)} \\
& +5 q^{\frac{1}{2}} r_{B} B_{1}
\end{aligned}
$$

where the expression of $B_{1}$ is given in(30) and (32). Note that for $B_{1}=0$, the expression in (35) leads to the $T$-stress expression for a three term representation. Equation (37) can be rewritten as follows:

$$
T \approx \frac{T_{A}-q^{\frac{1}{2}} T_{B}}{1-q^{\frac{1}{2}}}+\frac{5 \sqrt{3}\left(q^{\frac{1}{2}} K_{I_{A}}-K_{I_{B}}\right)}{4 \sqrt{2 \pi r_{B}}\left(1-q^{\frac{3}{2}}\right)}
$$

where $T_{A}$ and $T_{B}$ are obtained from (27). These are the $T$ stresses evaluated by the data, provided by $R_{A}$ and $R_{B}$, respectively, with a two term approach. 
Again, when considering the aluminium material $(v=1 / 3$, $f_{l}=2 / 3$ and $\left.\kappa=1 / 2\right),(36)$ can be expressed as:

$$
T \approx-\frac{E}{2}\left[\frac{\varepsilon_{r r_{A}}-q^{\frac{1}{2}} \varepsilon_{r_{B}}-3\left(\varepsilon_{\theta \theta_{A}}-q^{\frac{1}{2}} \varepsilon_{\theta \theta_{B}}\right)}{1-q^{\frac{1}{2}}}-\frac{5 q^{\frac{1}{2}}\left(q^{\frac{1}{2}} \varepsilon_{r r_{A}}-\varepsilon_{r r_{B}}\right)}{1-q^{\frac{3}{2}}}\right]
$$

Finite element analysis

Based upon the stress and rectangular strain rosette methods described above, we used the FEA with ANSYS software to determine the SIF $K_{I}$ and the $T$-stress under mode I loading.

\section{Finite element model}

The standard test using a Central Cracked Plate (CCP) specimen is shown in Figure 3. Also, we have reported in the same figure the dimensions of the sample. The thickness is 6 $\mathrm{mm}$ in a plane strain state. The width of all samples is maintained at $\mathrm{w}=50 \mathrm{~mm}$, while, the length of the crack is variable. For the calculations, the values of $a / w$ are taken equal to $0.2,0.3$ and 0.4 . Due to the symmetry, only one half of the CCP specimen is considered. In the crack tip region, 24 rows of elements were used. Each row consists of iso-parametric quadratic triangular mesh with $0.05 \mathrm{~mm}$ size. A square root singularity in the stress/strain field was produced at the crack tip by considering quarter point scaling between the circumferential rows of nodes surrounding this region (Figure 4). The specimen's material is the aluminum T6- 6082 with the mechanical properties: $\mathrm{E}=75000 \mathrm{MPa}, v=0.33$ and $\mathrm{K}_{\mathrm{IC}}=29$ $\mathrm{MPa} \cdot \mathrm{m}^{1 / 2}$.

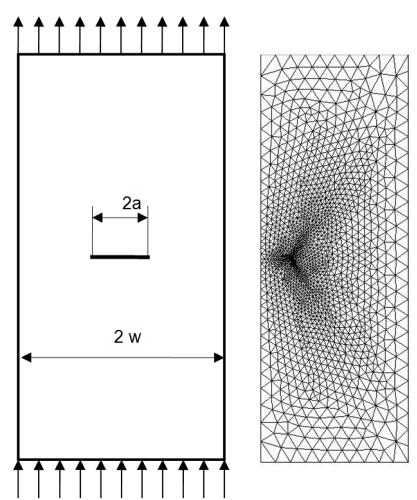

Fig. 3. Plate specimen with central crack under uniaxial tension.

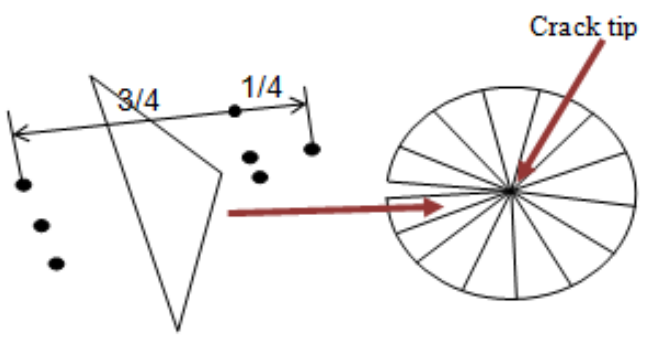

Fig. 4. Singular elements around the crack tip.

\section{E. Results and discussion}

We calculated the SIF obtained by placing the gages at different radii from $2 \mathrm{~mm}$ to $42 \mathrm{~mm}$. The obtained results of the SIF $K_{I}$ are shown in Figure 5. However, when using two rosettes, $K_{I}$ is very stable regardless of the gage position in zone II [17]; i.e. for $\mathrm{a} / \mathrm{w}=0.2$ the distance is less than $16 \mathrm{~mm}$ and for important ratios of $\mathrm{a} / \mathrm{w}$, the distance is up to $30 \mathrm{~mm}$. This result is in good agreement with the theory findings because the order of the asymptotic expansion in the case of two gages is higher. These results are compared to those obtained with the displacement method implemented in the FE software that we used. Figure 6 shows the variation of the Tstress as a function of the rectangular rosettes position with respect to the crack tip. The results are compared to those obtained by the stress method proposed in [43], $\mathrm{T}=\sigma_{\mathrm{xx}}-\sigma_{\mathrm{yy}}$ for $\theta=0$, for the three ratios $\mathrm{a} / \mathrm{w}(0.2,0.3$ and 0.4$)$. One can observe that the use of a single rosette requires a position close to the crack tip, where the stress field is very unstable. However, when the order of the asymptotic expansion is equal to 2 (case of two rectangular rosettes), the results become in good agreement with those of the stress method. Otherwise, singular elements in the FE calculations allow to a better approximation of the stress field near the crack tip. Thereby our results in terms of T-stress, obtained with the stress method, are very stable compared to those of the literature.
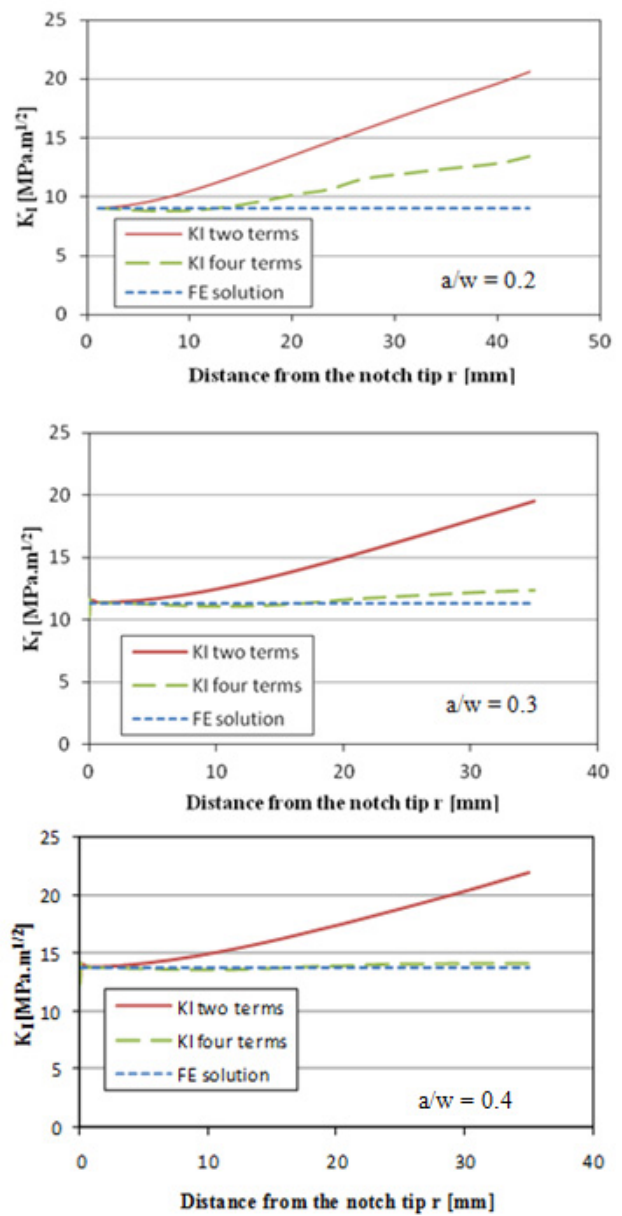

Fig. 5. SIF for (a) $\mathrm{a} / \mathrm{w}=0.2$, (b) $\mathrm{a} / \mathrm{w}=0.3$ and (c) $\mathrm{a} / \mathrm{w}=0.4$. 


\section{CONCLUSION}

In this paper we have proposed a simple method for determining the mode I SIF $\left(K_{I}\right)$ and $T$-stress using one or two strain gage rosettes. A five term solution was derived from the generalized Westergaard stress functions in order to give an experimental approach for measuring $K_{I}$ and $T$-stress. In fact, the use of one or two strain gage rosettes, placed in an only one orientation, is an important property of this method. Two specific cases were considered in reducing the five term theory to a simple and practical approach. We have shown, on the one hand, that a single rectangular rosette with suitable placement and orientation can be used to provide measurement of $K_{I}$ and $T$-stress while accounting for the effect of some higher order terms. On the other hand, two strain gage rosettes placed in two discrete positions with the same orientation are capable to provide the information necessary to evaluate $K_{I}$ and $T$-stress from a four term representation.
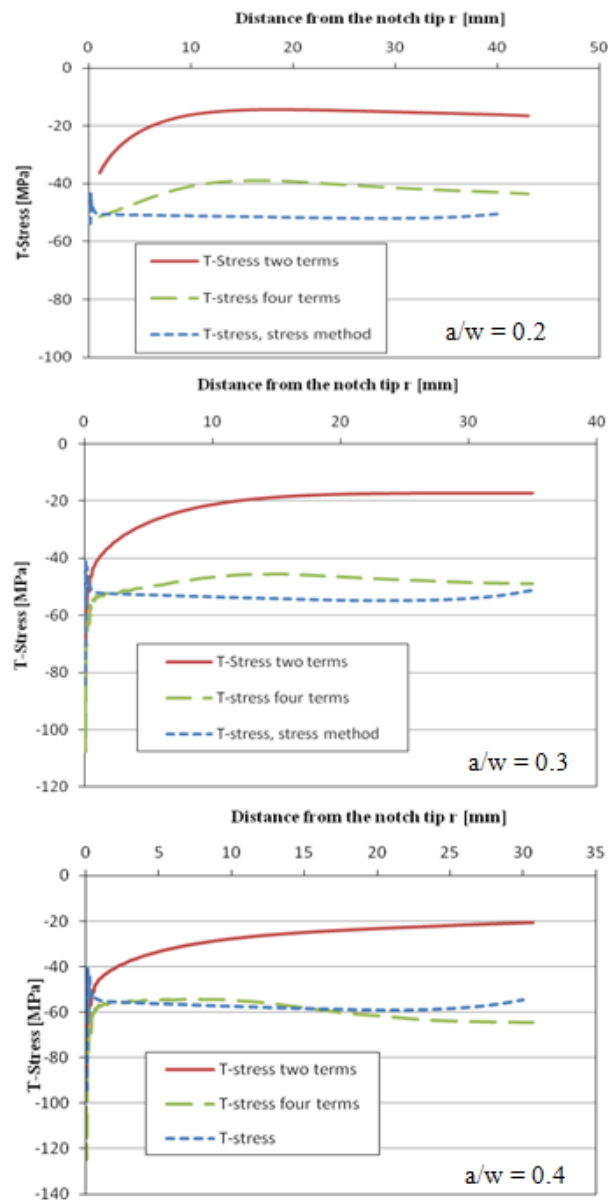

Fig. 6. T-Stress for (a) $\mathrm{a} / \mathrm{w}=0.2$, (b) $\mathrm{a} / \mathrm{w}=0.3$ and (c) $\mathrm{a} / \mathrm{w}=0.4$.

\section{REFERENCES}

[1] M. L. Williams, "On the stress distribution at the base of a stationary crack", Journal of Applied Mechanics, No. 24, pp. 109-114, 1957

[2] D. E. Richardson, J. G. Goree, "Experimental Veri_cation of a New Two-parameter Fracture Mode", Fracture mechanics: twenty-third Symposium, ASTM STP 1189, pp. 738-750, 1993
[3] Y. J Chao, S. Liu, B. J. Broviak, "Brittle Fracture: Variation of Fracture Toughness with Constraint and Crack Curving Under Mode I Conditions", Experimental Mechanics, Vol 41, No. 3, pp. 232-241, 2001

[4] G. R. Irwin, "Discussion of the Dynamic Stress Distribution Surrounding a Running Crack - A Photoelastic Analysis", Proceedings of the Society for Experimental Stress Analysis, Vol. 16, No. 1, pp. 9396,1958

[5] N. Fleck, "Finite element analysis of plasticity-induced crack closure under plane strain conditions", Engineering Fracture Mechanics, Vol. 25, No. 4, pp. 441-449, 1986

[6] B. Cotterell, J. R. Rice, "Slightly curved or kinked cracks", International Journal of Fracture, Vol. 16, No. 2, pp. 155-169, 1980

[7] N. A. Fleck, J. W. Hutchinson, Z. Suo, "Crack path selection in a brittle adhesive layer", International Journal of Solids and Structures, Vol. 27, No. 13, pp. 1683-1703, 1991

[8] J.S. Langer, A.E. Lobkovsky, "Critical examination of cohesive-zone models in the theory of dynamic fracture", Journal of the Mechanics and Physics of Solids, Vol. 46, No. 9, pp. 1521-1556, 1998

[9] R. J. Sanford, Principles of Fracture Mechanics, Prentice Hall, New York, 2003.

[10] R. M. Bonesteel, D. E. Piper, A.T. Davinroy, "Compliance and KI calibration of double cantilever beam (DCB) specimens", Engineering Fracture Mechanics Vol. 10, No. 2, pp. 425-428, 1978

[11] J.C. Newman, "Stress-intensity factors and crack-opening displacements for round compact specimens", International Journal of Fracture, Vol. 17, No. 6, pp. 567-578, 1981

[12] E. E. Gdoutos, P. S. Theocaris, "A photoelastic determination of mixedmode stress- intensity factors", Engineering Fracture Mechanics, Vol. 18, No. 3, pp. 87-96, 1978

[13] T. H. Hyde, N. A. Warrior, "An improved method for the determination of photoelastic stress intensity factors using the westergaard stress function", International Journal of Mechanical Sciences, Vol. 32, No. 3, pp. $265-273,1990$

[14] M. Mahinfalah, L. Zackery, "Photoelastic determination of mixed mode stress intensity factors for sharp reentrant corners", Engineering Fracture Mechanics, Vol. 52, No. 4, pp. 639-645, 1995

[15] P. S. Theocaris, "Local yielding around a crack tip in plexiglas", Journal of Applied Mechanics, Vol. 37, No. 2, pp. 409-415, 1970

[16] M. Konsta-Gdoutos, "Limitations in mixed-mode stress intensity factor evaluation by the method of caustics", Engineering Fracture Mechanics, Vol. 55, No. 3, pp. 371-328, 1996

[17] J. W. Dally, R.J. Sanford, "Strain-gage methods for measuring the opening-mode stress intensity factor, KI”, Experimental Mechanics, Vol. 27, No. 4, pp. 381-388, 1987

[18] S. Swamy, M.V. Srikanth, K.S.R.K. Murthy, P.S. Robi, "Determination of complex stress intensity factors of complex configurations using stra in gages", Journal of Mechanics of Materials and Structures, Vol. 3, No.7, pp. 1239-1255, 2008

[19] G. R. Irwin, "Analysis of stresses and strains near the end of a crack traversing a plate", Journal of Applied Mechanics, Vol. 24, pp. 361-364, 1957

[20] A. S. Kobayashi, Experimental techniques in fracture mechanics, SEM Monograph, Iowa State University Press, 1973

[21] A. S. Kobayashi, iBocing Company, Document No. D2-23552, 1962

[22] R. J. Sanford, "A critical re-examination of the Westergaard method for solving opening-mode crack problems", Mechanics Research Communications, Vol. 6, No. 5, pp. 289-294, 1979

[23] J. W. Dally, J.R. Berger, "A strain gage method for determining KI and KII in a mixed mode stress field", The proceedings of the 1986 SEM spring conference on experimental mechanics. New Orleans, LA; , pp. 603-612, 1986

[24] J. W. Dally, D.B. Barker, "Dynamic measurements of initiation toughness at high loading rates", Experimental Mechanics Vol 28, No. 3, pp. 298-303, 1988

[25] A. Shukla, B.D. Agarwal, B. Bhushan, "Determination of stress intensity factor in orthotropic composite materials using strain gages", Engineering Fracture Mechanics, Vol. 32, No. 3, pp. 469-477, 1989 
[26] S. K. K. Hanna, A. Shukla "Development of stress field equations and determination of stress intensity factor during dynamic fracture of orthotropic composite materials", Engineering Fracture Mechanics, Vol 47, No. 3, pp. 345-359, 1994

[27] S. K. K. Hanna, A. Shukla "On the use of strain gages in dynamic fracture mechanics”, Engineering Fracture Mechanics, Vol. 51, No. 6, pp. 933-948, 1995

[28] J. Wei, J. H. Zhao, "A two-strain-gage technique for determining mode I stressintensity factor", Theoretical and Applied Fracture Mechanics, Vol. 28, No. 2, pp. 135-140., 1997

[29] J. H. Kuang, L. S. Chen, "A single strain gage method for KI measurement”, Engineering Fracture Mechanics, Vol. 51, No. 5, pp. $871-908,1995$

[30] A. Dorogoy, D. Rittel, "Optimum location of a three strain gauge rosette for measuring mixed mode stress intensity factors", Experimental Mechanics, Vol. 75, No. 14, pp. 4127-4139, 2008

[31] J. R. Berger, J. W. Dally, "An overdeterministic approach for measuring KI using strain gages", Experimental Mechanics, Vol. 28, No. 2, pp. $142-145,1988$

[32] H. Sarangi, K. S. R. K. Murthy, D. Chakraborty, "Radial locations of strain gages for accurate measurement of mode I stress intensity factor", Materials \& Design, Vol. 31, No. 6, pp. 2840-2850, 2010

[33] H. Sarangi, K. S. R. K. Murthy, D. Chakraborty, "Optimum strain gage location for evaluating stress intensity factors in single and double ended cracked configurations", Engineering Fracture Mechanics, Vol. 77, No. 16, pp. 3190-3203, 2010

[34] H. Sarangi, K. S. R. K. Murthy, D.Chakraborty, "Experimental verification of optimal strain gage locations for the accurate determination of mode I stress intensity factors", Engineering Fracture Mechanics, Vol. 110, pp. 189-200, 2013

[35] J. R. Rice, "Limitations to the Small-scale Yielding Approximations for Crack Tip Plasticity", Journal of the Mechanics and Physics of Solids, Vol. 22, No. 1, pp. 17-26, 1974

[36] S. G. Larsson, A. J. Carlsson, "Influence of Non-singular Stress Terms on Small Scale Yielding at Crack Tips in Elastic-plastic Materials", Journal of the Mechanics and Physics of Solids, Vol. 21, No. 4, pp. 263277, 1973

[37] G. E. Cardew, M. R. Goldthorpe, I. C. Howard, A. P. Kfouri, "On the elastic T-term", In: Fundamentals of Deformation and Fracture: Eshelby Memorial Symposium, 1985
[38] A. P. Kfouri, "Some evaluations of the elastic T-term using Eshelby's method", International Journal of Fracture, Vol. 30, No. 4, pp. 301-315, 1986

[39] T. Nakamura, D. M. Parks, "Determination of Elastic T-stress along Three-dimensional Crack Fronts Using Interaction Integral", International Journal of Solids and Structures, Vol. 29, No. 1, pp. 15971611, 1992

[40] B. S. Henry, A. R. Luxmoore, "Three-dimensional evaluation of the Tstress in centre cracked plates", International Journal of Fracture, Vol. 70, No. 1, pp. 35-50, 1995

[41] J. Sladek, V. Sladek, P. Fedelinski, "Integral Formulation for Elastodynamic Tstresses", International Journal of Fracture, Vol. 84, No. 2, pp. 103-116, 1997

[42] B. Yang, K. Ravi-Chandar, "Evaluation of Elastic T-stress by Stress Di erence Method", Engineering Fracture Mechanics, Vol. 64, No. 5 , pp. 589-605, 1999

[43] M. R. Ayatolahi, M. J. Pavier, D. J. Smith, "Mode I cracks subjected to large T stress", International Journal of Fracture, Vol. 117, No 2, pp. $159-174,2002$

[44] F. A. Diaz, E. A. Patterson, R. A. Tomlinson, J.,R. Yates, "Measuring stress intensity factors during fatigue crack growth using thermoelasticity", Fatigue \& Fracture of Engineering Materials \& Structures, Vol. 27, No. 7, pp. 571-583, 2004

[45] J. R. Yates, M. Zanganeh, R. A. Tomlinson, M. W. Brown, F. A. D. Garrido, "Crack paths under mixed mode loading", Engineering Fracture Mechanics, Vol. 75, No. 3-4, pp. 319-330, 2008

[46] M. Zanganeh, R. A. Tomlinson, J. R. Yates, "T-stress determination using thermoelastic stress analysis", The Journal of Strain Analysis for Engineering Design, Vol 43, No. 6, pp. 529-537, 2008

[47] M. Zanganeh, R. A. Tomlinson, J. R. Yates, "T-stress determination using digital image correlation", Society for Experimental Mechanics11th International Congress and Exhibition on Experimental and Applied Mechanics, pp. 511-517, 2008

[48] M. J. Maleski, M. S. Kirugulige, H. V. Tippur, "A method for measuring mode I crack tip constraint under static and dynamic loading conditions", Experimental Mechanics 44, No. 5, pp. 522-532, 2004

[49] J. Rosakis, K. Ravi-Chandar, “On crack-tip stress state: an experimental evaluation of three-dimensional effects", International Journal of Solids and Structures, Vol. 22, No. 2, pp. 121-134, 1986 